\title{
Reduction in the use of benzodiazepines and cyclopyrrolones in general practice
}

\author{
$\begin{array}{lll}\text { Received (first version): } 19-S e p-2007 & \text { Accepted: } 25-\text { Nov-2007 }\end{array}$
}

\begin{abstract}
${ }^{\star}$
In 2003, the Danish Minister for the Interior and Health instructed general practitioners to reduce prescriptions of benzodiazepines (BZD) and cyclopyrrolones (CP) by 50\%. However, no effective methods were specified. In Denmark, it is estimated that there are approximately 100,000 BZDdependent patients, constituting approximately $2 \%$ of the population.

Objective: This article describes the implementation of a successful, simple and voluntary intervention to reduce the use of dependence-inducing drugs, while at the same time challenging practitioners' ingrained habits and prejudices in this field. Methods: The rules implemented were essentially in accordance with the official Danish rules, such that a prescription for BZD and CP could only be issued for one month at a time, and only following consultation. Use was monitored using the Danish registration system, Ordiprax, which monitors sales of prescription medicine. Two Danish general practices, comprising a patient base of approximately 2300 were studied. With the exception of the severely physically or mentally ill, all users of BZD and CP were included. Results: After $2 \frac{1}{2}$ years, the use of BZD and CP was reduced by $75 \%$ and $90 \%$, respectively. The reorganization of prescription patterns was seen to be significantly easier than physicians had expected. During the first three months, only four to five additional visits per week per 1000 patients were required. Subsequently, this number was stabilized at one to two additional visits. The usual collaborative partners, such as psychiatrists, homecare services, hospitals and substance abuse units were essentially not deployed. No serious withdrawal effects arose.

Conclusion: The implementation of the aforementioned simple procedures is to be recommended for the prescription of BZD and CP drugs, as the effect is immediate and easily attainable, with a reasonable work input required on the part of general practitioners.
\end{abstract}

Keywords: Benzodiazepines. Physician's Practice Patterns. Denmark.

\footnotetext{
*Viggo K. JØRGENSEN. Specialist in General Medicine, General practitioner. Medical advisor, Medicine Team. Primary Care Unit, Region Midtjylland. Holstebro (Denmark).

Birgit S. TOFT. Pharmacist, PhD. (pharm.). Quality development consultant. Medicine Team, Primary Care Unit, Region Midtjylland. Holstebro (Denmark).
}

\author{
REDUCCIÓN DEL USO DE \\ BENZODIAZEPINAS Y \\ CICLOPIRROLONAS EN MEDICINA \\ GENERAL
}

\section{RESUMEN}

En 2003, el Ministerio de Interior y Salud danés instruyó a los médicos generales para que redujeran las prescripciones de benzodiacepinas (BZD) y ciclopirolonas (CP) en un 50\%. Sin embargo, no se especificaron métodos efectivos. Se estima que en Dinamarca hay aproximadamente 100.000 pacientes dependientes de BZD, lo que constituye el $2 \%$ de la población.

Objetivo: Este artículo describe la implantación de una intervención voluntaria, simple y con éxito para reducir el uso de medicamentos inductores de dependencia, mientras que ataca los hábitos y prejuicios adquiridos por los médicos generales en esta área.

Métodos: Las reglas implantadas estaban esencialmente de acuerdo con las reglas oficiales danesas, como que una receta de BZD o CP sólo podría darse para un mes de una sola vez, y sólo después de una consulta. El uso se monitorizó mediante el sistema de registro danés, Ordiprax, que monitoriza las ventas de medicamentos de prescripción. Se estudiaron dos consultas generales que atienden una población de aproximadamente 2300. Con la excepción de los enfermos físicos o mentales graves, se incluyó a todos los usuarios de BZP y CP.

Resultados: Después de 21/2 años, el uso de BZP y $\mathrm{CP}$ se redujo en un $75 \%$ y $90 \%$ respectivamente. La reorganización de los esquemas de prescripción fue considerada significativamente más fácil de lo que esperaban los médicos. Durante los tres primeros meses, sólo se necesitaron de 3 a 4 consultas adicionales por semana por 1000 pacientes. Posteriormente, este número se estabilizó en 1 a 2 consultas adicionales. Los colaboradores habituales, tales como psiquiatras, servicios domiciliarios, hospitales y unidades de dependencia no fueron esencialmente sobrecargados. No aparecieron efectos de abandono graves. Conclusión: Se recomienda la implantación de los mencionados procedimientos simples para la prescripción de $\mathrm{BZD}$ y $\mathrm{CP}$, ya que el efecto es inmediato y fácilmente alcanzable, con un trabajo necesario de los médicos generales razonable.

Palabras clave: Benzodiazepinas. Modelos de ejercicio médico. Dinamarca. 


\section{INTRODUCTION}

Benzodiazepines (BZD) and cyclopyrrolones (CP) are medications indicated for the short term relief of severe anxiety in association with insomnia. ${ }^{1}$ The excess use of these medications (defined as use leading to tolerance and/or dependence, as well as depression, cognitive impairment, disinhibition and psychomotor imbalance) ${ }^{1}$ is a major international problem that has not yet been satisfactorily solved, even though it has been the subject of much attention. ${ }^{1}$ In 2003 the rules defined in the Danish Circular covering addictive medicine were tightened up. These rules determine that the prescription of sleeping medicine should be limited to 1-2 weeks, and that anxiolytics should not be prescribed for more than 4 weeks before a reevaluation takes place. ${ }^{2}$ During the same year the Danish Minister for the Interior and Health instructed general practitioners to reduce consumption by $50 \%$.

This tightening of the rules is considered to be professionally well founded, as it is believed that approximately 100.000 Danes are dependent on these drugs. ${ }^{3}$ The use of these drugs is associated with side effects, of which the most common are those influencing intellectual functions. ${ }^{4}$ Adaptation to these side effects takes place to a very limited degree, even after long periods of use of these drugs. The elderly are especially vulnerable, due to altered elimination. This can lead to concentrations of BZD in the blood being 4 times as high as expected. Among consumers of BZD and CP aged over 65 years, the risk of falls with subsequent hip fractures is increased by $50-110 \%$. $^{5,6}$ These drugs are considered to represent a danger for users of motor vehicles, and a study of elderly patients has shown a 2-5 times increase in the risk of traffic accidents. ${ }^{7,8}$ This risk of traffic accidents is of the same magnitude as for those who operate motor vehicles under the influence of alcohol. ${ }^{8}$

A significant proportion of consumers develop tolerance to such a degree, that abstinence symptoms are observed upon withdrawal. ${ }^{4}$ Withdrawal symptoms may include serious effects such as suicidal impulses and abstinence cramps, as well as lesser effects such as anxiety, unrest, increased dream activity, insomnia and melancholic tendencies. ${ }^{9}$ This is probably the leading reason why patients are trapped in their use of these drugs.

To reduce use in accordance with the existing rules enhanced measures in two general practitioners' clinics were implemented against the use of addictive medicine. Over a 11/4-year period, both practices were able to reduce the use of benzodiazepines on average by $50 \%$, while reducing the use of cyclopyrrolones by $75 \% .{ }^{10,11}$ In this paper, the $2 \frac{1}{2} 2$-year follow up is published, and offers a tentative estimate of the number of patients who have ceased their use of these drugs. The results presented here are significantly better than had been expected, and we feel that there is a great demand among practitioners for simple methods and techniques to tackle these withdrawals.

\section{METHODS}

The data presented here arises from two general practices in Thyborøn, Denmark, comprising approximately 2300 patients. In collaboration with the Public Health Department in Ringkjøbing Amt, both practices agreed to "work by the rules" from January 1, 2004. Due to geographical constraints, the intervention was initiated in both practices with patients living in Thyborøn town (approximately $2 / 3$ of the patients) and from January 1,2005 all patients from both practices were involved. Accordingly, the intervention had duration of $2 \frac{1}{2}$ years for $2 / 3$ of the patients, and $1 \frac{1}{2}$ years for the remaining third.

The intervention included the anatomical therapeutic chemical (ATC)-code classified N05BA (e.g. oxazepam (Alopam) and diazepam (Hexalid)) and N05CD (e.g. flunitrazepam (Flunipam) and triazolam (Halcion)) benzodiazepines, as well as N05CF cyclopyrrolones (e.g. zopiclon (Imovane, Imozop) and zolpidem (Stilnoct)). The medications included here comprise all groups of benzodiazepines and cyclopyrrolones (with the exception of those specifically indicated for the treatment of epilepsy) available in Denmark during the intervention The internet site of the Danish Institute for Rational Pharmacotherapy (IRF; www.Ordiprax.dk) was used for evaluation, due to ease of access as well as a high degree of coverage of the required material.

The material compiled by the IRF originates from data reported by pharmacies to the Drug Statistics Register of the Danish National board of Health covering the sale of prescription drugs. For each prescription, the practitioner's identification code, the patients central person registration (CPR) number and the products specific product identification number are registered, where the latter comprises the products ATC-code, package size as well as the total number of defined daily doses (DDD) in the package.

Ordiprax is divided into two categories: county data and medical practice data. Medical practice data comprises the individual practices prescriptions to own patients, redeemed at a Danish pharmacy, and is normally only visible to the practitioner.

Ordiprax data was received already standardized with respect to sex and age, relative to the reference (national) population. The level of error in the registered values in Ordiprax is ca. $4 \%^{12}$ and this level of error will have no effects on the conclusions reached in this article.

\section{The intervention}

To support the intervention, a patient as well as staff guide and a waiting room poster were prepared. Practitioners were issued the IRF' $s$ book "Benzodiazepiner i almen praksis" [Benzodiazepines in General Practice] as well as C. Heather Ashton's book "Benzodiazepines: How they work and how to withdraw". 4,9 
The practitioners' intervention consisted of

- The elimination of telephone prescription of BZD and CP.

- The issue of prescriptions only following personal consultation.

- The issue of medicine sufficient for a single months use only.

- A discussion at each consultation regarding future treatment requirements as well as a possible phased reduction of treatments.

The Press covered the project locally as well as nationally, through television, radio and newspaper coverage.

\section{Inclusion criteria}

With the exception of the severely physically or mentally ill, all users of BZD and CP were included in the intervention. The term severe physical disorder covered patients suffering from a terminal disease, or patients where disease characteristics were such that the prescription of medical drugs was primarily performed by a specialist unit. Severe psychiatric disorders generally covered patients whose treatment was being monitored by a psychiatrist. The treatment of patients excluded from this study was not changed as a result of this project.

The Danish National Health Service in Ringkjøbing County as well as the local medical association had no objections to the increase in consultations arising from this study.

\section{Units}

The reduction in prescriptions was described by the following: The total DDD (defined daily doses) for every 1000 of the physicians own patients per quarter calculated for the last two quarters of 2005 and the first two quarters of 2006 is compared to the average DDD for every 1000 of the physicians own patients for the four quarters of 2003 (immediately prior to the initiation of the intervention), in order to eliminate seasonal variance. Accordingly, the reduction in prescriptions was registered over a period of $2 \frac{1}{2}$ years. The intervention covered all included patients who had contact to the two practices with respect to BZD and CP during this period.

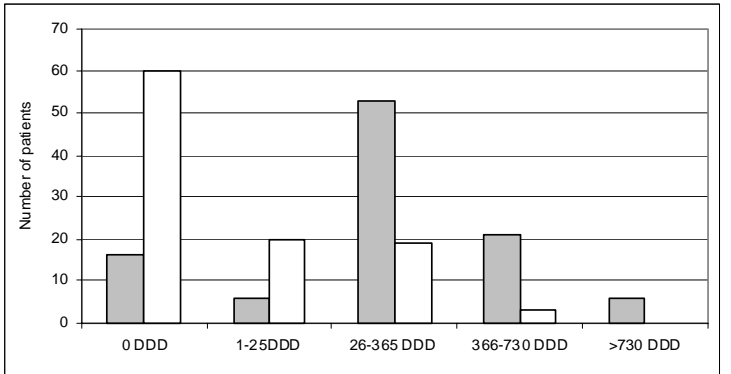

Figure 1. Distribution grouping of patients' total use of benzodiazepines and cyclopyrrolones, in defined daily doses (DDD) per year, for patients in both practices;

$\mathrm{n}=102$. Only patients associated with the practices for the duration of the intervention are included. The dark columns indicate the distribution prior to the interventions; the light columns indicate distribution subsequent to the intervention.
A series of user groups were defined, delimiting 5 levels of use of BZD and CP (Figure 1). The patients included in the intervention were allocated to these five groups, before and after the intervention. The allocation of patients before the intervention was defined by their use of BZD and $\mathrm{CP}$ in 2003. The allocation following the intervention was carried out on the basis of practitioners' estimates $2 \frac{1}{2}$ years later, with the second quarter of 2006 as the initial source of data (multiplied by four to obtain an estimated use). Only patients associated with the practices during the entire period are included.

A practice's use is characterized as being high when its use of BZD and CP is among those of the $25 \%$ highest ranked practices in Ringkjøbing County. Conversely, a practice is considered to have a low use when it is among the $25 \%$ lowest ranked practices. An average use is characterized as being among the remaining $50 \%$ of practices.

The significance of the reduction in the consumption, before and after the initiation of the intervention, was determined using the two-tailed Ttest for two samples with equal variance (as determined using the F-test).

\section{RESULTS}

In all, 126 patients were included in the intervention, and of these 102 were associated with one of the two practices during the entire period of the intervention. Of demographic data, only age was registered for both practices. $89 \%$ of patients included in the intervention had a patient age greater than 45 years, with $53 \%$ of patients falling in the group 45-65 years. The patient-age distribution of both practices are essentially identical (Figure 2). A total of 13 patients died during this period, while 11 either joined or left the practices. The practitioners estimated that four patients changed practice as a direct consequence of the project. These four patients had an average BZD consumption of 490 DDD in 2003, corresponding to 123 DDD per quarter. By way of comparison, 27 patients in both practices had a similar or higher consumption in 2003. Twelve patients were excluded from the intervention, as they did not conform to the inclusion criteria.

In the patients' user groups (Figure 1) there was a sharp increase in the number of patients in the groups with low consumption of benzodiazepine (N05BA, N05CD) and/or cyclopyrrolone (N05CF), and a concomitant reduction in the number of patients in the higher consumption groups. Similarly, the number of patients with zero consumption increased dramatically, from 16 to 60 persons (Figure 1), following the initiation of the intervention.

The percentage reduction for anxiolytics of the benzodiazepine group (N05BA) was $89 \%$ for practice 1 , and $66 \%$ for practice 2 . Prior to the intervention, the consumption in practice 1 was 1544 DDD per for every 1000 of the physician's own patients per quarter on average in 2003 , considered to be a medium-high consumption. In the second 
quarter of 2006, the use of 176 DDD per 1000 patients was considered to be one of the counties lowest consumption for the preceding year. Initially, the rate of prescription for practice 2 was $79 \%$ higher than that of practice 1 , and practice 2 was considered to have one of the highest rates of prescription in Ringkjøbing County. Consumption fell from 2762 DDD to 840 DDD per 1000 patients in the second quarter of 2006 , and this consumption must continue to be considered as being high. In practice 2 there are still a few patients who are following phased withdrawal as a result of the intervention. The combined reduction in both practices of anxiolytics of the benzodiazepine group was $75 \%$ (Figure 3 ).

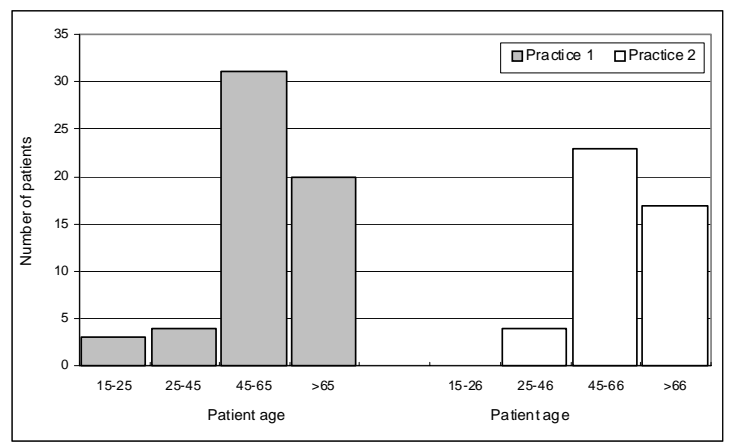

Figure 2. Patient-age grouping of benzodiazepine (N05BA, N05CD) and/or cyclopyrrolone (N05CF)-consuming patients, $n=102$. Only patients associated with the practices for the duration of the intervention are included. The dark columns indicate the distribution for Practice 1; the light columns indicate distribution for Practice 2.

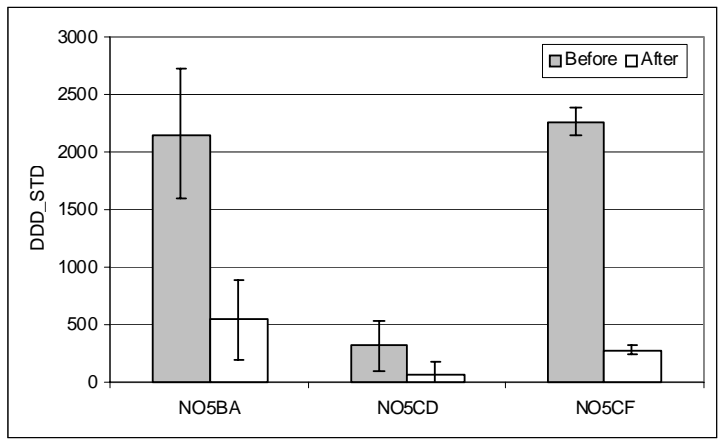

Figure 3: Development in the consumption for two Danish practices, before and after the initiation of the measures for the reduction of benzodiazepines (N05BA, N05CD) and cyclopyrrolones (N05CF). Data compiled before the intervention is derived from prescriptions are quarterly averages for the four quarters of 2003; data for prescriptions issued after the initiation of the measures are for the last two quarters of 2005 and the first two quarters of 2006 . Error bars denote the $95 \%$ confidence interval of the means. "Before" and "After" values are significantly different, $(P<0.05$; two-tailed T-test for samples with equal variance)

The use of hypnotica of the benzodiazepine group (N05CD) was low (as defined in "Materials and Methods") for both practices at the onset of the intervention. In effect, the consumption of this group of drugs has ceased. During the last year, both practices have alternated among the lowest consuming practices in the county. For certain periods, practice 1 has been registered as being completely without consumption. Consumption in the second quarter of 2006 was registered as 78 DDD. By searching in the practices' computer systems the individual consumer could be identified. Accordingly, the 78 DDD correspond to a prescription renewal for a single patient, originally issued by a specialist in psychiatry.

The consumption of hypnotica from the cyclopyrrolone group (N05CF) was high in 2003 in practice 1, and only marginally lower for practice 2 . The reduction in consumption after $2 \frac{1}{2}$ years was $83 \%$ for practice 1 . The reduction was most marked during the first half year following the start of the intervention. In practice 2 the reduction was 93\%. This reduction was more evenly distributed over the period the intervention was in effect. The combined reduction in the consumption of cyclopyrrolones in both practices was $88 \%$ (Figure 3 ).

In contrast, at the national level, the consumption of the benzodiazepines N05BA and N05CD fell by $8,8 \%$ and $1.9 \%$ in 2004 , respectively, while the consumption of the cyclopyrrolones N05CF increased by $3,8 \% .^{13}$ In both practices, new consumers were included, and they were also covered by the new rules.

During the first three months (first quarter, 2004) for Practice 1, 3996 consultations and 62 house calls per 1000 patients were registered, corresponding to an increased work input of four to five consultations per week per 1000 patients as a result of the intervention (corresponding to an increase of 5,8\%). This increase workload relative to the period prior to the intervention fell to an additional one to two consultations (corresponding to an increase of $1,9 \%$ ) after $2 \frac{1}{2}$ years. This estimate is based on the practitioner's own registration of the increased number of consultations significantly relevant for the intervention that arose as a direct consequence of the project.

In most cases, after a short period consensus was reached with the patient regarding future use. The workload of homecare services was not increased as a consequence of the project. During this period, a single referral to a practicing psychiatrist was made, as well as a telephonic inquiry to the community mental healthcare.

No patient was referred to phased reduction at the hospital, or to the Addiction Unit in Ringkjøbing County. No patients developed serious withdrawal symptoms (e.g. suicidal impulses, abstinence cramps), as determined by specific questioning during the monthly consultation. Lesser withdrawal symptoms observed included anxiety, unrest, increased dream activity and insomnia as well as melancholic tendencies. No apparent increase in alcohol consumption was noted as a result of the intervention, although this observation is not based on a systematic study. Conversational therapy was not used, and no official complaints from the Danish Public Health Services Board or the chief Medical Officer regarding, for example, malpractice or negligence as a direct consequence of the intervention were reported. Both practitioners considered the project to be less burdensome than they had initially expected. 


\section{DISCUSSION}

During recent years, increased focus has been placed on the over use of BZD and CP. The Ministry for the Interior and Health has initiated an information campaign aimed at reducing use, and the Institute for Rational Pharmacotherapy has assumed the responsibility of training practitioners. At the national level, the use of BZD and CP was reduced by $5 \%$ in 2005 . The present study shows that training and motivation are key factors for a successful intervention. No specialist system is able to cope with the withdrawal from treatment of 100.000 patients. The problem can and must be addressed at the level of general practice. The present study shows that this is feasible.

However, the initiative is somewhat weakened by the fact that the Circular $^{2}$ includes a dispensation allowing for continued prescription to elderly patients, due to the fact that the use of hypnotics and anxiolytics is considered to be ingrained in the life pattern of these patients. Accordingly, the Circular permits the prescription of drugs which, after a few months use, are associated with serious side effects. Elderly patients experience a doubled risk of hip fractures, with a $20 \%$ increase in mortality after a single year. ${ }^{5}$ In the literature, warnings against the operation of motor vehicles are evident. ${ }^{8}$ The quality of life of patients is decreased, and their intellectual faculties are reduced. In certain cases, this may lead to pseudodemens. ${ }^{14}$

There are many social expenses associated with drug dependency. These include both direct as well as indirect expenses, including loss of production and increased health costs. In 1997 the annual expense associated with a single drug-dependant patient was calculated to be 48.000 Euro. ${ }^{15}$ Clearly, drug dependency has an economic impact, and attention should be drawn to this fact.

Previous initiatives to reduce the consumption of benzodiapines in general practice have been reported in the literature. A reduction of $57 \%$ in the consumption of benzodiapines and codein following the circulation of brochures as well as the initiation of individual withdrawal therapies by practitioners was revealed following a Norwegian study. ${ }^{16} \mathrm{~A}$ Danish study ${ }^{17}$ utilized a questionnaire asking patients to reflect on their individual situations, as well as their actual and expected future consumption, and a reduction of $55 \%$ in the consumption of benzodiapines was noted. In New York $^{18}$, new rules implemented in 1989 included a triplicate prescription policy for benzodiapines, requiring physicians to obtain, pay for and use serial numbered, triplicate forms for the prescription of benzodiapines, leading to a decrease of $30-60 \%$ in prescriptions. Similarly, an English audit study ${ }^{19}$ revealed that a simple audit of the prescription of these drugs could lead to a reduction in consumption of $16 \%$. Finally, an individually tailored, resource-intensive treatment with a focus on the individual patients ${ }^{20}$, comprising a course of supervised benzodiazepine withdrawal has been shown to be satisfactory in $48 \%$ of cases.
In contrast to these previous, resource-intensive interventions, the present study differentiates itself from previous studies in its simplicity, in the low workload impact of the intervention, and its voluntary basis. Accordingly, this study contributes significantly to the overall sum of knowledge in this field. It is important in this study to understand that the patient is the centre of the intervention at all times, and no adjustments are made to prescriptions without the involvement of the patient. The monthly consultations are inspiring for both patient and practitioner, while contributing to draw attention to problems related to the consumption of dependency-producing drugs. In addition, circulars and waiting room posters, as well as the significant support the project received from both electronic and printed local media contributed to the success of the project.

Elderly patients were not exempted from the monthly consultations, and were therefore not exempted from the monthly evaluation. The withdrawal from treatment of elderly patients with a daily use was of course one of the challenges encountered in this project; however, it was possible to motivate most of the members of this group. The absolutely most difficult patient was typically the elderly nursing home resident, but withdrawal from treatment was often successful here.

Figure 1 indicates that it is the group of users consuming 26-365 DDD per year that has the greatest advantage of the intervention. The number of users consuming 366-730 DDD per year is reduced, while the group of heavy consumers ( $>730$ DDD per year) is eliminated. It is important to realize that patients from the middle- and lowconsumption groups may be former highconsumption patients, and reductions in the highconsumption group can be expected to be greater over time.

A limitation of the findings presented here is the scale of the intervention. Accordingly, a cost-benefit analysis of the intervention is not feasible. With respect to clinical consequences, the question of concomitant changes in prescriptions of antidepressants and antipsychotics is the subject of a separate article under preparation. It should also be noted that the results are based on the actual ordination data for BZD and CP for the specific practices and time periods, and that these data do not take into account patients excluded from the intervention, or patients joining or leaving either of the two practices.

The required literature regarding withdrawal is readily available $e^{4,9-11}$ and can be read in a few hours. Practical experiences with respect to withdrawal are described in the Danish journal Månedsskrift for Praktisk Lægegerning. ${ }^{21}$ The concept is considered to be universally adaptable, as approximately 80 practitioners representing 124.000 patients in Ringkjøbing County have introduced these rules to date. Responses have been positive. 


\section{CONCLUSIONS}

It is recommended that the following few and simple rules are implemented in general practice:

- The elimination of telephone prescriptions.

- Issue of prescriptions only following consultation.

- Prescriptions are limited to one month at a time

Every month, the patient and the practitioner are required to consider whether the actual level of use is appropriate, or whether withdrawal should be initiated. The introduction of waiting room posters and circulars regarding prescription rules, as well as press coverage can be expected to contribute significantly to the success of similar projects.

Finally, it is recommended that a critical approach be implemented with respect to "exemptions" for the elderly, as is evident in the Danish Circular covering addictive medicine. This weakens the value of the intervention for the reduction of addictive medicine, and leaves what is probably the most important and weakest group of addicted patients with a potentially lethal medication use.

\section{ACKNOWLEDGEMENTS}

Thanks are extended to Dr. Hans Holmsgaard, Thyborøn, for his cooperation as well as for his willingness to contribute material.

\section{CONFLICT OF INTEREST}

VKJ receives support from the Ministry of Health and Prevention pool for studies and initiatives related to drug issues, including compliance.

\section{References}

1. Srisurapanont M, Critchley J, Garner P, Maneeton B, Wongpakaran N. Interventions to reduce benzodiazepine prescribing. Cochrane Database Syst Rev. 2005 Jan 24;(1).Protocol.

2. Communication regarding the prescription of addictive drugs. Directive CIR 12 from 13/01/2003. Copenhagen; Danish National Board of Health, 2003.

3. Hansen EH, Helweg-Jørgensen S. Dependency on psycho pharmaceutics from a patient perspective [in Danish] Faculty of Pharmaceutical Sciences. Lægemiddelforskning 1999: 23.

4. Danish Medicines Agency. Institute for Rational Pharmacotherapy. Benzodiazepine in general Practice [In Danish]. 2004; Sep;(1):1-41. Available from URL: http://www.irf.dk/dk/publikationer/vejledninger/behandligsvejledning benzodiazepiner.htm [Accessed 2008 March 22]

5. Wang PS, Bohn RL, Glynn RJ, Mogun H, Avorn J. Zolpidem use and hip fractures in older people. J Am Geriatr Soc. 2001,49:1685-1690

6. Cumming R, Le Couteur DG. Benzodiazepines and Risk of Hip Fractures in Older People. CNS Drugs. 2003;17:825-837

7. McGwin G, Sims RV, Pulley L, Roseman JM. Relation among chronic medical conditions, medications, and automobile crashes in the elderly: a population-based case-control study. Am J Epidemiol. 2000;152(5):424-431.

8. Vester JC, Veldhuijzen DS, Volkerts ER. Residual effects of sleep medication on driving ability. Sleep Med Rev. 2004;8(4):309-325.

9. Ashton $\mathrm{CH}$. Benzodiazepines: How they work and how to withdraw. The Ashton Manual, Aug. 2002. [Online]. Available from URL: http://www.benzo.org.uk/manual/index.htm [Accessed 2008 March 22].

10. Jørgensen VRK, Toft BS, Fogh MS. Reducing the use of addictive drugs in clinical practice [in Danish] Ugeskr Laeger. 2006;168:1636-1640.

11. Jørgensen VRK, Toft BS, Fogh MS. Reducing the use of benzodiazepines and cyclopyrrolones in clinical practices. Pharmacy Practice 2006;4(2):74-78.

12. Ordiprax: a tool for doctors and regions. Fact sheet from the Danish Medicines Agency [online]. Available from URL:http://www.ordiprax.dk [Accessed 2008 March 22].

13. Danish Medicines Agency. The consumption of benzodiazepines and benzodiazepine related drugs [online]. Available from URL: http://www.dkma.dk/visUKLSArtikel.asp?artikelID=11644 [Accessed 2007 Sep 16]

14. Torper J, Steine S. Seponation of benzodiazepine- how is the experience of the users [In Norwegian] Tidsskr Nor Laegeforen. 2004;124(18):2342-2344.

15. Gyldmark M, Hansen EH. The social costs of dependency on psycho pharmaceutics [in Danish] Faculty of Pharmaceutical Sciences. Lægemiddelforskning 1997:36-37.

16. Mouland G. A letter to benzodiazepine users--an efficient way to reduce the prescription [in Norwegian]. Tidsskr Nor Laegeforen. 1997;117:3097-3100.

17. Andreasen CM, Errebo-Knudsen L, Kristensen KA. Patient information might reduce the use of benzodiazepines in general practice.[in Danish] Ugeskr Laeger. 1989;145:2968-2970.

18. Weintraub M, Singh S, Byrne L, Maharaj K, Guttmacher L. Consequences of the 1989 New York State triplicate benzodiazepine prescription regulations. JAMA.1991;266(17):2392-2397.

19. Holden JD, Hughes IM, Tree A. Benzodiazepine Prescribing and Withdrawal for 3234 Patients in 15 General Practices. Fam Pract. 1994;11:358-362.

20. Ashton H. Benzodiazepine Withdrawal: outcome in 50 patients. Br J Addiction. 1987;82:665-671.

21. Jørgensen VRK. Benzodiazepine reduction in practice [In Danish]. Månedskr Prakt Lægegern. 2006;84:333-339. 